\title{
Interpreting experiences of students using educational online technologies to interact with teachers in blended tertiary environments: A phenomenological study
}

\author{
Kimberley Tuapawa \\ University of Newcastle, Australia
}

\begin{abstract}
Although educational online technologies (EOTs) have transformed the delivery of learning in higher education, significant EOT challenges have impeded their effectiveness, preventing widespread implementation. The persistence of these challenges suggests that tertiary education institutes (TEIs) have experienced a gap in understandings about the reality of key stakeholders' EOT needs. This research made a phenomenological interpretation of key stakeholders' EOT experiences, to establish their current EOT needs and challenges and provide a basis from which to recommend methods for effective EOT support. It analysed the EOT experiences of 10 students and 10 teachers from New Zealand and Australia and interpreted the meanings of the phenomena through an abstraction and articulation of local and global themes. This paper is the first in a series of six publications that presents the local themes. It documents the interpretations of students' experiences with teachers, in reference to their use of four types of EOTs: online conference tools, learning management systems, blog sites and lecture capture tools. These interpretations, which include descriptions of stakeholders' EOT challenges, helped to inform a set of recommendations for effective EOT use, to assist TEIs in their efforts to address EOT challenges and meet stakeholders' needs.
\end{abstract}

\section{Introduction}

Educational online technologies (EOTs) have dynamically transformed the delivery of higher education, creating extraordinary opportunities for enhanced learning and teaching. In an era of unparalleled growth, their improved functionalities and affordances have revolutionised methods of knowledge access and engagement, engendering significant advances across the higher education sector. Traditional learning spaces have evolved into vibrant blended tertiary environments (BTEs), and channels of content dissemination have switched from didactically styled "traditional, face-to-face courses to ... online courses” (Picciano, 2015, p. 148).

These digital transformations foreshadow thrilling prospects for teachers and students, the key stakeholders in BTEs. Predictions about online learning suggest that virtual universities and off-campus sites are the trends in the future of higher education (Peppers, 2016), and as "the pace of change” rapidly accelerates, "hybrid classes will proliferate" (Anderson, Boyles, \& Rainie, 2012, p. 17). This is now happening, as "millions of students [take] online courses ... [giving] evidence that this modality is meeting a clear demand" (Allen \& Seaman, 2015, p. 21). Similar forecasts indicate that the digital delivery of coursework via online technologies will revolutionise higher education (Anderson et al., 2012). Results already show that "since 2010, there has been an increase in the use of most technologies for learning” (Gosper, McKenzie, Pizzica, Malfroy, \& Ashford-Rowe, 2014, p. 298).

Despite the remarkable growth and demand for online learning, significant obstacles impede the use of EOTs. Some of these challenges include attitudinal inclinations and institutional barriers, inadequacies in instructional design support (Panda \& Mishra, 2007) and a "lack of training" or ineffective or insubstantial training (Merfert, 2016, p. 1). Others include resistance to change, inefficient EOT usage, lack of motivation and technical limitations (Tuapawa, 2016). These challenges pose a clear risk to the future success of BTEs (Moskal, Dziuban, \& Hartman, 2013) and create complications which limit stakeholders' abilities to perform their roles effectively.

Significant efforts have been made to better understand EOT challenges. These have resulted in considerable research, with diverse contributions to the literature. Some studies have focused on the integration of technologies into learning environments (Moore, 2013), the affordances and effectiveness of learning technologies in higher education (Arenas, 2015; El-Khalili \& El-Ghalayini, 2015), obstacles to the adoption of online learning (Bacow, Bowen, Guthrie, Lack, \& Long, 2012) and e-learning 
challenges faced by academics (Islam, Beer, \& Slack, 2015). However, while "our research foundation is rich” (Passey, 2013, p. 209), not all obstacles have been amply identified and addressed.

The persistence of these problems suggests that TEIs have experienced a gap in understanding the reality of key stakeholders' EOT needs. Over time, these needs have shifted and evolved, and in an environment of rapid technological change have not been understood and addressed effectively. The dynamic nature of the environment in which TEIs operate means that their relevance is dependent on their ability to evolve and adapt to meet their stakeholders' needs. However, doing this effectively requires that TEIs have current, in-depth understandings of their stakeholders' EOT challenges, at a level that enables the delivery of informed, relevant and meaningful support.

Through a phenomenological approach, this research aimed to interpret key stakeholders' EOT experiences, establish their current EOT needs and challenges and provide a basis from which to recommend methods for effective EOT support. Using a 5-step qualitative analysis of data, it examined the EOT experiences of ten students and ten teachers, categorised these to reflect the nature of their interactions with other key entities and then interpreted the meanings of the phenomena through an abstraction and articulation of local and global themes. The global themes delivered a broad set of interpretations about the meaning of stakeholders' EOT experiences with other students, other teachers and content, and the local themes developed meanings that were specific to stakeholders' use of individual EOTs.

This paper is the first in a series of six publications that present the local themes of this research, through written interpretations that articulate the meaning of the phenomena. It documents students' EOT experiences with teachers, in reference to their use of four different EOTs: online conference tools (Adobe Connect), learning management systems (LMS) (Blackboard, Moodle), blog sites (WordPress), and lecture capture/webcast tools (Echo360). Included in its interpretations are descriptions of stakeholders' EOT challenges, which deliver a realistic portrayal of the phenomena to strengthen understandings of stakeholders' needs. The interpretations helped to inform a set of recommendations for the effective use of EOTs in student-to-teacher interactions. These were designed to assist TEIs in their efforts to adapt to meet stakeholders' EOT needs by providing a basis from which to tackle EOT challenges and deliver relevant and meaningful EOT support.

To lay a foundation for this study, the author undertook preliminary research, which clarified and verified issues from literature, and created a basis for the selection of interview participants. This identified EOTs in BTEs (Tuapawa, in press), produced a classification system for EOTs (Tuapawa, Sher, \& Gu, 2014, 2016), identified key stakeholders in BTEs (Tuapawa, 2016b), identified the EOT challenges of key stakeholders (Tuapawa, 2016a) and discussed a key challenge (resistance to change) in using EOTs (Tuapawa, 2015).

\section{Methodology}

The collection and analysis of this data was guided by the methodology of interpretive phenomenology, which aimed to make an interpretation (rather than only a description) of the meanings of participants' experiences (Padilla-Diaz, 2015; Sloan \& Bowe, 2014; Yuksel \& Yildirim, 2015). Aligned to the tenets of Heideggerian philosophy (Reiners, 2012), this study of experience (Friesen, Henriksson, \& Saevi, 2012) abstracted and articulated emergent themes from key stakeholders' experiences into a series of written interpretations, to bring to light the phenomena (Sloan \& Bowe, 2014) of EOT use. This methodological choice was influenced by the research aim, which sought to understand and interpret key stakeholders' EOT experiences in BTEs, the central research questions (Marelli, 2016), which were: What were the EOT experiences of key stakeholders in BTEs? and What interpretations could be drawn from their meanings? and finally, the researcher's "interest in the meaning of a phenomenon as it [was] lived by other subjects” (Englander, 2012, p. 14).

A group of ten students and ten teachers from institutes in New Zealand and Australia were selected as participants using a purposive sampling strategy (Yuksel \& Yildirim, 2015). This method ensured that data would be obtained from individuals with first-hand experiences of the phenomena (Waters, 2016), in support of the aim of phenomenology, to understand a particular phenomenon "from the point of view of the lived experience" (Englander, 2012, p. 16). The rationale for this number was based on literature 
about phenomenological research. Englander (2012), for example, indicated that a large sample size, especially when it concerned qualitative research, was not a prerequisite for generalisable results. Nicholls (2009b) explained that "phenomenological studies ... commonly use[d] as few as five ... participants" (p. 639). Rawat (2014) similarly stated that normally "four or five respondents" were selected for in-depth interviews. It was on this basis that 20 participants were chosen (Englander, 2012; Nicholls, 2009b; Padilla-Diaz, 2015).

Further criteria were set to refine the selection of participants. To be interviewed, they had to be teachers on full-time tenure with an accredited tertiary institute, delivering an academic course in a blended learning mode. If they were students, they had to be aged 18 years or older, enrolled full time with an accredited tertiary institute and in an academic course delivered in a blended learning mode. Teachers were identified from university website profiles of academic staff teaching in New Zealand or Australia. Students were identified with the assistance of a staff member at each institute. Invitations sent to participants indicated that participation was voluntary. Attempts were made to recruit both male and female participants.

The rationale for the selection of only teachers and students was based on a study by the author (Tuapawa, 2016b), which identified key stakeholders in BTEs and described their contributions. Through a review of literature about key stakeholder identification (Chapleo \& Simms, 2010; Coleman et al., 2013; Gross \& Godwin, 2005; Leisyte, Westerheijden, Epping, Faber, \& De Weert, 2013; Mainardes, Alves, \& Raposo, 2013; Power \& Morven-Gould, 2011; Sanderson, 1997; Singh \& Weligamage, 2012; Tang \& Hussin, 2011; Wagner, Hassanein, \& Head, 2008) and qualitative interviews with 13 blended learning experts from New Zealand, Australia and Canada, students and teachers were shown to be among those identified most prominently and frequently as key stakeholders in BTEs. Students were identified as key stakeholders by 12 of 13 experts because of the need for them to "buy into" blended learning, "participate fully, and be convinced" of its value (Tuapawa, 2016b, p. 5). Their ability to support discussion, deliver feedback, and enhance "connectedness or community” (Balaji \& Chakrabarti, 2010, p. 17) contributed significantly to the success and value of learning experiences (Tuapawa, 2016c). Teachers also were identified as key stakeholders by 11 of the 13 experts, and considered by nine of them to be among those contributing most significantly to BTE success, due to their immediate and direct involvement in the teaching and learning process and their day-to-day focus on and influence over blended learning experiences.

Phenomenological interviews, known for being "exceedingly common in qualitative research studies" (Nicholls, 2009b, p. 640) were considered appropriate for gathering idiomatic data. These interviews followed a semi-structured format and were conducted via online video-conferencing technology (Skype) and audio recorded using Pamela software. Participants set aside at least 45 minutes of uninterrupted time to engage (Simon \& Goes, 2012) and were asked a series of 27 questions. They responded with first-hand narratives (Dowling \& Brown, 2012; Moustakas, 1994; Waters, 2016) of their EOT experiences, which included descriptions about their use of different types of EOTs to interact with different sets of key entities (students, teachers and content). Specifically, participants were asked for a "description of a situation in which [they had] experienced the phenomenon" (Englander, 2012, p. 25) of using an EOT in a BTE. The situational aspects of their descriptions were vital to the research, since understandings of a phenomenon [i.e. using an EOT] had to be "connected to a specific context in which the phenomenon [was] experienced” [i.e., a BTE] (Englander, 2012, p. 25).

To encourage a frank portrayal of the phenomena, the interview questions were carefully constructed to elicit descriptions of experiences that included EOT challenges. Probes were used to clarify the meanings of responses and encourage participants' in-depth explanations (Lester, 1999; Penner \& McClement, 2008; Waters, 2016) and rich descriptions of their “conscious experience” (Martin, 2010, p. 1). As a result, participants detailed "the phenomenon in their consciousness" (Wikispaces, 2015, p. 1), rendering valuable idiomatic narratives that supported understandings of the phenomena.

The questions were also framed to stimulate participants' recollections of their EOT experiences or encounters with different key entities. These types of encounters were based on the classification by interaction taxonomy augmented by Culatta (2011) and the original classification proposed by Moore (1989). This taxonomy categorised technologies by the relationship between learners and other parties. The first three interaction types of the original taxonomy were learner to expert, learner to learner, and 
learner to content. Culatta (2011) presented a fourth category: learner to context. Tuapawa, Sher, and Gu (2014, 2016), proposed a fifth category: learner to media. These categories were adapted to facilitate and structure interviews with teachers, as follows: (1) teacher to student, (2) teacher to teacher, (3) teacher to content, (4) teacher to context, and (5) teacher to media. The use of the relationship-based classification for structuring the questions helped refine participants' experiences into relevant and recognisable EOT interactions. It revealed distinctions between phenomena occurring in different key relationships, and set in place a structure through which to organise the themes, or essential meanings, about the phenomena (Waters, 2016). Table 1 outlines the questions asked of students about their EOT experiences with teachers.

Table 1

Interview questions

\begin{tabular}{ll}
\hline Interaction type & Questions \\
\hline Learner to teacher & Question 1: \\
& (a) Describe an experience in which you used an EOT in a learner-to-teacher \\
interaction while studying in a BTE? \\
(b) Did you face issues or challenges using the EOT in this case? Explain. \\
(c) What do you think would be a solution to this issue? \\
(d) What do you think would have helped you make more meaningful use of this \\
(e) DOT?
\end{tabular}

To encourage conversation and promote a connected, comfortable atmosphere, the researcher adopted a personable, inquisitive and mindful disposition (Yin, 2015). Thoughtful engagement with participants, a sensitivity towards their challenging issues and conversational qualities in "talking to people” (Nicholls, 2009a, p. 533), helped to solicit their perspectives (Saldana, 2011, p. 75). It also ensured that "sufficient interview data” (Saldana, 2011, p. 34) was obtained, until the point of saturation was met and repetition occurred.

Recordings of the interviews were transcribed using pre-formatted question-and-answer templates. This process, although time-consuming, enabled and compelled the researcher to develop an intimate level of familiarity with the content (Daniels, 2016) and prepare it for examination. Yin's (2015) five phases of qualitative data analysis, compiling, disassembling, reassembling, interpreting, and concluding, were used to frame and structure the analysis. Table 2 demonstrates the link between these five phases, and the phenomenological techniques used.

Table 2

Phases of qualitative analysis vs interpretive phenomenological research techniques

\begin{tabular}{|c|c|c|}
\hline Stage & Stage description & Phenomenological research technique \\
\hline (1) & Compiling & Data transcripts imported and arranged \\
\hline (2) & Disassembling & Data descriptions coded using nodes \\
\hline (3) & Reassembling & Memos used to develop understandings of phenomena \\
\hline (4) & $\begin{array}{l}\text { Interpreting (thematic analysis } \\
\text { and interpretation of data) }\end{array}$ & $\begin{array}{l}\text { Local and global themes abstracted, meanings of } \\
\text { experiences articulated through written interpretations }\end{array}$ \\
\hline (5) & $\begin{array}{l}\text { Concluding (conclusions and } \\
\text { recommendations) }\end{array}$ & $\begin{array}{l}\text { Interpretations used to inform recommendations for } \\
\text { effective EOT use that supports stakeholders' needs. }\end{array}$ \\
\hline
\end{tabular}

NVivo software (QSR International, 2015) was used to import, compile, and organise the transcripts into a logical structure (Yin, 2015). Data from these documents were disassembled into smaller pieces and coded. Using the Nodes coding function, the data was separated into categories that corresponded to the interview questions. These nodal categories, which were labelled using truncated versions of the questions, represented the data clearly and enabled it to be logically assigned, labelled, referenced and contained in manageable groupings (Williams, 2003). Table 3 demonstrates the link between the node labels used for coding the data, and the interview questions. 
Table 3

Nodes linked to student interview questions

\begin{tabular}{|c|c|c|}
\hline Node & Node description & Related question \\
\hline (1) & Learner-to-teacher Q1a & $\begin{array}{l}\text { Describe an experience in which you used an EOT in a learner-to- } \\
\text { teacher interaction while studying in a BTE. }\end{array}$ \\
\hline (2) & Learner-to-teacher Q1b & $\begin{array}{l}\text { Did you face issues or challenges using the EOT in this case? } \\
\text { Explain. }\end{array}$ \\
\hline (3) & Learner-to-teacher Q1c & What do you think would be a solution to this issue? \\
\hline (4) & Learner-to-teacher Q1d & $\begin{array}{l}\text { What do you think would have helped you make more meaningful } \\
\text { use of this EOT? }\end{array}$ \\
\hline (5) & Learner-to-teacher Q1e & Did you experience benefits in using this EOT? Explain. \\
\hline
\end{tabular}

The data were then reassembled, which required that they be transferred from the nodal position into analytic memos (Yin, 2015), where they could be used to elaborate ideas and insights (QRS International, 2015) and help develop understandings about the phenomena (Saldana, 2011). Finally, the data were subjected to an interpretation, through a thematic analysis, which involved an abstraction and synthesis of local and global themes (Padilla-Diaz, 2015) using a reflexive perspective (Sloan \& Bowe, 2014). In this process, themes, the essential meanings of or aspects associated with the phenomena, were discovered through thoughtful engagement with the descriptions of the stakeholders' experiences (Waters, 2016), into a series of written interpretations, to bring to light the phenomena (Sloan \& Bowe, 2014) of EOT use. The global themes, which were broad in significance, generated high-level interpretations of the phenomena. The local themes, developed through a deep but narrow scope, derived meanings from the use of individual EOTs.

The highlighted example in Figure 1 conceptualises how the data were gathered, transcribed, sorted and coded and stored using nodes, refined into a student-to-teacher based memo and interpreted through an analysis of local themes. These provided the basis for the discussion of results in this paper.

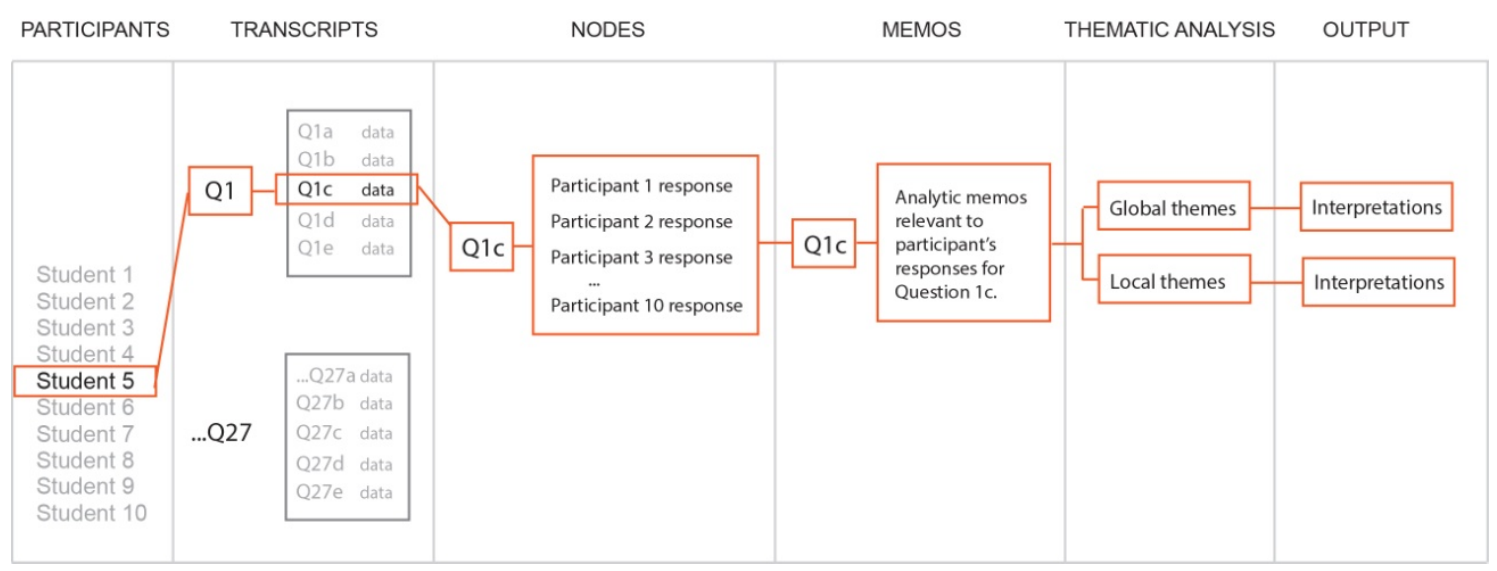

Figure 1. Process of data analysis

\section{Results and discussion}

This section articulates the local themes that were abstracted from students' EOT experiences with teachers. These are delivered as a series of written interpretations of students' lived experiences (Sloan \& Bowe, 2014; Waters, 2016) and organised into five sections according to the EOT types students had identified: online conference tool (Adobe Connect), learning management system (LMS) (Blackboard), LMS (Moodle) blog site (WordPress) and lecture capture/webcast tool (Echo360). Each of these sections includes a description of the EOT brand exemplar, a series of local themes related to its use and an interpretation of students' experiences, which include their comments on EOT issues and challenges, potential usage, solutions and benefits. The labels used to describe the EOT types are based on the pentexonomy (Tuapawa et al., 2014, 2016), a robust, contextualised and multi-dimensional framework for categorising EOTs. 


\section{EOT: Online conference tool Example: Adobe Connect}

\section{Description}

Adobe Connect is a conferencing platform that offers real-time collaborative online meeting experiences, from small-group collaboration to large-scale webinars (Adobe Systems Software Ireland Ltd, 2015). It is being used in institutes "as an online virtual classroom, but also ... in quite flexible ways to ... enable conversations often out of time" (Tuapawa, in press, p. 4).

\section{Themes}

Easy to use, accessible across devices, affords flexible learning, technical and hardware issues, bandwidth problems, teachers' ineffective use

\section{Experiences}

Students' descriptions of their experiences using Adobe Connect to interact with their teachers revealed this tool to be simple to use, easily accessible, in some ways flexible, in other ways limiting and fraught with technical problems. Distance learners with online access to its real-time class sessions generally viewed their interactions with teachers as useful and beneficial. The tool's flexible nature enabled them to engage while "in the class, but at home", where learning could occur without distraction. Describing the value added to his learning through Adobe Connect, one student acknowledged that he "[got] more, doing it from home" than in class. The students who missed live sessions appreciated being able to view a recording of the lecture. Others, however, experienced problems using Adobe Connect to interact with their teachers. While real-time sessions were described as "useful for distance learners" and "beneficial", one student was averse to engaging with others in class, citing reluctance to interrupt lectures with a question, because "you [didn't] want to put someone who [was] speaking off, you'[d] be stopping the whole class from learning”. Others expressed their annoyance with various technical issues, which included "problems with positioning of microphone, [sound] quality, bandwidth". Some experienced negative impacts on their learning due to "rustiness on the lecturer's part ... not clicking on the right things at the right time". Problems arose as the teacher "[tried] to manage Adobe Connect while teaching ... [often] stopping the class to type [or] shrink windows, [which] ... interrupted class time, [consuming] "a good 10-15 seconds in limbo".

\section{EOT: $\quad$ LMS \\ Example: Blackboard}

\section{Description}

Blackboard is a complete e-learning software platform that delivers a comprehensive course management support (Blackboard Inc, 2015). It can serve as a repository for learning resources or be used as "an elearning portal around a particular programme of work, course or sets of activities" (Tuapawa, in press, p. 4).

\section{Themes}

Enables engagement for distance learners, more practical than face-to-face, frustration at lack of access to learning resources, broken links, restricted access levels, design inconsistencies, non-standard page customisations, navigation issues, expectations not communicated clearly

\section{Experiences (messaging and discussion forums)}

Students' experiences using Blackboard to interact with their teachers via messaging and discussion forums were described as "really difficult", "really hard", "frustrating" and "notorious". Students were frustrated with teachers who did not use Blackboard to respond in a timely manner, or at all, to questions they had raised. One asserted that his lecturer failed to "respond to anyone. It's frustrating." The lack of communication from their teachers left students feeling confused, neglected and abandoned. "You post a question, but don't know when you're going to get a response." As to the severity of this problem, another student bemoaned having a "lecturer who [hadn't] responded in 3 weeks", the result of which was "driving me insane". Another described her lecturer's lack of responsiveness as "notorious". "Considering [that] this [was] the only way of interacting with the lecturer, you feel let down that they [were] not answering your questions.” The situation worsened after students had waited, only to receive a 
late response that “[didn't] give you what you need[ed].” Clarifying with a follow-up question seemed pointless, because "asking again [was] hard." "Although you'[d] clearly stated what you want[ed] ... it [got] lost in translation.”

Another issue causing frustration for students involved the occurrence of broken links, or links for which access was denied. For one student, “video links [didn’t] work, or the link [was] locked”. While trying to access online resources, he noted that "a lot of the links [were] bad", making it difficult to "move around without pressing back, back." Although the teachers "put up good stuff you, you [couldn't] get into it". Students then had to "spend hours and hours trying to find answers to questions", which was "very frustrating". They also expressed frustration over design inconsistencies that occurred across course pages, which resulted from non-standard customisations applied to page layouts by teachers. Non-generic page designs created navigational issues, confusion and a situation whereby students wasted time searching for familiar elements. Explaining the issue, one student asserted that "every page ... set up [in Blackboard was] slightly different to the others", and so effort was expended on identifying the location of required texts. "It's a minefield", because to find what is needed, "you really ha[d] to trawl through it." They requested that teachers simply "put the same things in the same spots", work at "displaying it better ... [using] the right titles ... [and making it] easier to get around.”

Students also expressed frustration at the lack of clear statements about course and assignment expectations. These should be communicated through Blackboard, otherwise "interpreting what your lecturer want[ed was] really difficult". One student was frustrated at a lecturer who said "absolutely nothing [in response to a question, and] when they finally g[ot] around to answering, their answer ha[d] nothing to do with the question." Another student held that instead of delivering a helpful explanation, teachers simply "fob[bed] it off" with a recommendation to engage "problem-based learning, and discover [the answer] for yourself”. Despite negative experiences, students recognised the role Blackboard played in enabling engagement from distance learners, many of whom "work[ed] full-time" and f[ou]nd using this tool "more practical than standard face-to-face". Confirming its value, one student acknowledged that “without Blackboard, I couldn’t be a distance student at all.” Another remarked that "unlike in an offline environment", the use of Blackboard helped her to understand "very broadly where the whole class [was] up to”.

\section{EOT: $\quad$ LMS \\ Example: Moodle}

Description

Moodle is a platform which provides a robust, secure and integrated system for creating personalised learning spaces. It provides a set of learner-centric tools and collaborative learning environments that support education (Moodle, 2015). Its various features include "the chat mode, online forums, online quizzes”, links to “pre-recorded videos” and additional activity-based tools (Tuapawa, in press, p. 8).

Themes

Potential for extended features and use, affords flexible out-of-class learning, easy to use, unrestricted access to learning, teachers' ineffective use, teachers' inactivity and response times, dated layout and design, lack of training for tool, platform for shovelware

\section{Experiences}

Students' descriptions of their experiences using Moodle to interact with their teachers revealed positive views of this tool's functionality and potential for extended features and use, but negative views about teachers' inactivity and ineffective use of it. They were frustrated with teachers who "were not tech savvy ... [or] very active in Moodle." Teachers who failed to use Moodle effectively needed "more ... instruction and training" to accommodate "different age groups", such as "someone in their seventies [who would] absolutely struggle.” Interacting with teachers in Moodle was “frustrating”, it was “easier to flick an email”. Some students complained about the layout, design and general appearance of Moodle. "It looks dated. None of the 18-19-year olds use it ... it looks terrible, like something from the nineties”.

Some were annoyed at the lack of Moodle-based training. One student wanted "dedicated sessions, an idiot's guide to Moodle”, since he had found "lots of things ... on Moodle that [had not been] explained". Another voiced frustration about not having received "good orientation" to the system. "To the 
uninitiated, it was a minefield." For other students, the use of Moodle lay bare the failure of teachers "who [were] really good at their subject [but] really suck[ed] at lecturing, [those who were] not good at conveying it ... in an online situation." Disappointed, one student criticised his teacher's habit of shovelling "everything away online" by uploading notes which were simply read out during the lecture. "If I want[ed] that, I [could have] just sat at home and read what he's written. I want[ed] the lecture to add value to those notes, not be the notes."

Despite these unfortunate experiences, students acknowledged the role Moodle played in enabling engagement at "anytime, [without] having to be there". Having experienced the benefits of its unrestricted access to online learning activities, one student described enjoying the "freedom to [post a comment] anytime ... You [could] post it up, and not worry about it.” Moodle enabled users "to put a [problem] up there, and free [their] mind." They even imagined "more creative ways of using [Moodle]", and stated that the "potential [for its use was] endless." Others stated that for this to happen "more encouragement from tutors to actually use it” was needed. They suggested an incentivised approach.

\section{EOT: $\quad$ Blog site \\ Example: WordPress}

Description

WordPress is an online, open source website creation tool that provides an easy-to-use, powerful blogging and website content management system (iThemes Media, 2015). It is a "broadcasting and user construction tool, and media repository” with "low levels of fidelity” (Tuapawa et al., 2014, p. 47; 2016, p. 233)

Themes

Useful authoring capabilities, enables expression, valuable tool for communicating feedback and developing e-portfolios, anonymity valued, strict rules needed to guide conduct

\section{Experiences}

Students' descriptions of their experiences using WordPress to interact with their teachers revealed positive views of its authoring capabilities and as a platform for liberatory expression. The opportunities it provided for communication and creative writing strengthened its perceived value for students. One student enjoyed using WordPress to "express a viewpoint", believing it to be a valuable tool with which to "diar[ise] our experience". Another used it to develop and maintain an e-portfolio. WordPress enabled open and honest written feedback on particular issues in an unencumbered, safe and non-confrontational manner where students could enjoy "privacy ... and intimacy". One student valued "the relative anonymity ... to make honest judgements" on specific topics. He appreciated being able to communicate "when I wanted to, say what I wanted to, [without] having to make an appointment to get feedback". When on one occasion, he realised that although part of a group of students, he had done most of the work, he used the platform to "make an indirect grumble" to his teacher, being "emboldened" by the "relative anonymity" afforded by WordPress "to say what [he] wanted". Although the use of WordPress allowed him to experience a level of freedom, he felt that "stricter guidelines" around written conduct should be established.

\section{EOT: Lecture capture/webcast tool Example: Echo360}

\section{Description}

The Echo360 Active Learning Platform provides lecture capture and webcast capabilities, enabling instructors to record, edit and assign instructional videos, create media-rich course content for live or ondemand viewing, record classroom action and interaction and then turn these into lessons that students can replay on a device (Echo360, 2015).

Themes

Affords flexible out-of-class learning, repeatable recordings are valued, teachers' ineffective use of tool and attitude towards use, ineffective hardware use affects sound quality 


\section{Experiences}

Students' descriptions of their experiences using Echo360 to view their teachers revealed both positive and negative views about its perceived value. Those who missed live sessions appreciated being able to view a recording of the lecture. Stating why interacting with teachers using Echo360 was effective, one student explained that "a lot of guys work[ed] ... [so you didn't] have to work your job around your lecture times ... just go home and watch it". Viewing pre-recorded lectures enabled students to "listen over and over again and try to understand the points" without ever having to "miss a lecture". Others, however, experienced problems in using Echo360. One student simply complained that "the lecturers [were] not good at [using] it”. Some teachers "walk[ed] around the room and you los[t] a lot of what they sa[id]." Others "point[ed] to ... the slides [using laser pointers for those in class], but should [have] use[d] a mouse" to enable those viewing at a distance to follow along. Microphones and appropriate sound equipment needed to be used effectively "so that online learners c[ould] hear the questions and answers." Disappointed, one student described his teacher's apathetic attitude in using this tool, admitting how “they'[d] put YouTube videos into their lectures, and then the links or sound [wouldn't] work, and they'[d be] like "Oh well, just listen to it when you get home.” Disheartened at the apparent lack of concern, another student asked that teachers "care a little bit more”.

Students' experiences using EOTs to interact with teachers were varied and informative. Their descriptions indicated that effective EOT use contributed to enriched student-to-teacher interactions, whereas inefficient use created barriers that negatively impacted on learning. Students' vivid descriptions of EOT challenges delivered a realistic portrayal of the phenomena and demonstrated the extent to which these obstacles limited their engagement in learning. Some expressed concern, annoyance and impatience when confronted with technical or accessibility issues; others were perplexed, irritated, sceptical, and voiced their discomfort or confusion. Despite negative experiences, their recognition of the function EOTs had in facilitating engagement was evident. Students indicated that improvements to EOT functionality, accessibility and design would lessen certain obstacles, and improve their interactions with teachers. Their recommendations for solutions to challenges signalled that they wanted change and relevant support, to ensure their commitment to EOT use.

Teachers impacted students' experiences through attitudinal characteristics and their methods of EOT engagement with them. Experiences indicated students' strong expectations of support for learning from teachers. Teachers were counted on to use EOTs effectively to communicate, encourage and assist the learning process, "to master, design, and deliver strategies, techniques, and methods for teaching online courses" (Yang \& Cornelious, 2005, p. 1). Their "roles [were now] more critical in online learning environments" (Moore, 2013, p. 307) and their direct involvement with students, or with material intended for student use, contributed significantly to the success of learning experiences.

\section{Conclusion, recommendations and limitations}

This research made a phenomenological interpretation of key stakeholders' EOT experiences to strengthen understandings about their EOT needs and challenges and provide a basis from which to recommend methods for effective EOT support. It analysed the EOT experiences of ten students and ten teachers from TEIs in New Zealand and Australia and interpreted the meanings of the phenomena through an abstraction and articulation of local and global themes. This paper was the first in a series of six publications that presented the local themes of this research. It documented the interpretations of students' EOT experiences with teachers, in reference to their use of four different types of EOTs: online conference tools (Adobe Connect), LMS (Blackboard, Moodle), blog sites (WordPress) and lecture capture/webcast tools (Echo360). These interpretations, which delivered insights into the reality of students' EOT challenges and needs, helped to inform a set of recommendations for effective EOT use, to assist TEIs in their efforts to address EOT challenges and needs through relevant, meaningful EOT support.

The small sample size characteristically used in phenomenological studies makes it challenging to generalise results across large populations (Waters, 2016). However, the descriptions of key stakeholders' experiences provide a rich and authentic means from which to extract deep levels of knowledge about the phenomena. Although individual experiences were unique, their interpretations established themes that were common across homogenous participants. It is important to note that the views expressed by participants reflected the state of development of software at a particular point in time, the ways in which 
it was implemented and maintained and the manner in which it was used. Notwithstanding these realities, much can be gained from the comments of participants. Although an interpretive phenomenological approach supported the researcher's “interest in the meaning of a phenomenon as it [was] lived by other subjects”, it also permitted their personal preconceptions to affect the analysis of data (Englander, 2012, p. 14).

The interpretations in this research could be used to support understandings about other similar EOTs. For example, the themes drawn from students' experiences with Adobe Connect could in some cases be applied to Skype. This research has the potential to be replicated and applied to other TEI stakeholders, such as administrators or educational support staff, to strengthen understandings of their EOT challenges and needs. A summary of recommendations for addressing some of the EOT challenges described in students' experiences is outlined below:

- $\quad$ Teachers establish ground rules with the class before beginning sessions using Adobe Connect. Remind students to offer the respect and active listening skills to virtual speakers as they would for live speakers. Decide ahead of time how students will interact with other virtual participants (Adobe Systems Inc, 2010).

- Managers urge and facilitate teachers' ongoing needs-based training for LMS use, to ensure they have relevant skills to construct and deliver online courses effectively.

- Managers encourage teachers to engage best practices in course page design, employ effective design principles such as clarity, concision, familiarity, consistency with layout, positioning, size and colour (Garton, 2012).

- Teachers to employ good usability principles to make content learnable, efficient, memorable (Voyton, 2014). Organise content so it appears and operates in predictable ways through lists, menu items and clear structure.

- $\quad$ Teachers engage common rules of email and messaging etiquette, demonstrating professionalism and efficiency. Be concise and to the point, answer all questions and pre-empt further questions and use proper spelling, grammar and punctuation.

- Implement strategies to improve timeliness of teachers’ responses to students' questions. Students feel "personal help is really important” (Tuapawa, 2016a, p. 10). Teachers log in daily to read new discussions and participate where appropriate. Respond where necessary within 24 hours to demonstrate faculty presence in course (Northern Illinois University, 2016).

- $\quad$ Teachers consider providing or facilitating access to student training in using key LMS features and functions. Ensure guidelines to effective LMS use are provided.

- $\quad$ Teachers consider how live sessions are organised and recorded to ensure that in-class learning activities are delivered effectively to learners at a distance, for example, positioning of camera and microphone to record session clearly.

- Teachers ensure that all required online learning content is accessible to students at all times.

\section{References}

Adobe Systems Inc. (2010). Extending the classroom with Adobe Connect. Retrieved from http://www.kumc.edu/Documents/TLT/extend_the_classroom_connect.pdf

Adobe Systems Software Ireland Ltd. (2015). Adobe Connect. Retrieved from http://www.adobe.com/nz/products/adobeconnect.html

Allen, I. E., \& Seaman, J. (2015). Grade level: Tracking online education in the United States. Retrieved from http://www.onlinelearningsurvey.com/reports/gradelevel.pdf

Anderson, J. A., Boyles, J. L., \& Rainie, L. (2012). The future impact of the internet in higher education: Experts expect more-efficient collaborative environments and new grading schemes; they worry about massive online courses, the shift away from on-campus life. Washington, DC: Pew Research Centre. Retrieved from http://www.pewinternet.org/files/oldmedia/Files/Reports/2012/PIP_Future_of_Higher_Ed.pdf

Arenas, E. (2015). Affordances of learning technologies in higher education multicultural environments. Electronic Journal of E-Learning, 13(4), 217-227. Retrieved from http://www.ejel.org/issue/download.html?idArticle=432

Bacow, L. S., Bowen, W. G., Guthrie, K. M., Lack, K. A., \& Long, M. P. (2012). Barriers to adoption of online learning systems in U.S. higher education. Retrieved from 
http://www.sr.ithaka.org/sites/default/files/reports/barriers-to-adoption-of-online-learning-systems-inus-higher-education.pdf

Balaji, M. S., \& Chakrabarti, D. (2010). Student interactions in online discussion forum: Empirical research from 'media richness theory' perspective. Journal of Interactive Online Learning, 9(1), 1-22. Retrieved from https://pdfs.semanticscholar.org/a7c1/5dfdba9eff739a38dfdd6eed83d380280f98.pdf

Blackboard Inc. (2015). Welcome to the Blackboard Learning System. Retrieved from http://library.blackboard.com/docs/cp/learning_system/release6/student/Chapter_1_Welcome to the Blackboard_Learning_System.htm

Chapleo, C., \& Simms, C. (2010). Stakeholder analysis in higher education. Perspectives: Policy and Practice in Higher Education, 14(1), 12-20. doi:10.1080/13603100903458034

Coleman, T., Lovejoy, K., Shea, N., Graf, B., Marivate, V., Dwyer, M., ... Daser, D. (2013). Diverging perspectives on higher education: Challenges and opportunities. Retrieved from http://odl.rutgers.edu/wp-content/uploads/2015/03/pldi-2014-presentation.pdf

Culatta, R. (2011). Categorization of learning technologies. Innovative Learning. Retrieved from http://innovativelearning.com/instructional_technology/categories.html

Daniels, C. (2016). How to transcribe interviews. Retrieved from http://work.chron.com/transcribeinterviews-11397.html

Dowling, P., \& Brown, A. (2012). Doing research/reading research: Re-interrogating education. London: Routledge.

Echo360. (2015). Echo360 active learning. Retrieved from http://echo360.com/

El-Khalili, N., \& El-Ghalayini, H. (2015). Comparison of effectiveness of different learning technologies. International Journal of Emerging Technologies in Learning, 10, 56-63. Retrieved from http://onlinejournals.org/index.php/i-jet/article/view/4158

Englander, M. (2012). The interview: Data collection in descriptive phenomenological human scientific research. Journal of Phenomenological Psychology, 43, 13-25. doi:10.1163/156916212X632943

Friesen, N., Henriksson, C., \& Saevi, T. (Eds.). (2012). Hermeneutic phenomenology in education: Method and practice. Rotterdam: Sense. doi:10.1007/978-94-6091-834-6

Garton, J. (2012, January 18). Designing aesthetically pleasing Moodle courses. Opensource.com. Retrieved from https://opensource.com/education/12/1/designing-aesthetically-pleasing-moodlecourses

Gosper, M., McKenzie, J., Pizzica, J., Malfroy, J., \& Ashford-Rowe, K. (2014). Student use of technologies for learning - What has changed since 2010? In B. Hegarty, J. McDonald, \& S.-K. Loke (Eds.), Rhetoric and Reality: Critical perspectives on educational technology. Proceedings ascilite Dunedin 2014 (pp. 290-301). Retrieved from http://ascilite2014.otago.ac.nz/files/fullpapers/238Gosper.pdf

Gross, K., \& Godwin, P. (2005, September 1). Education’s many stakeholders. University Business. Retrieved from http://www.universitybusiness.com/article/educations-many-stakeholders

Islam, N., Beer, M., \& Slack, F. (2015). E-learning challenges faced by academics in higher education: A literature review. Journal of Education and Training Studies, 3(5), 102-112. doi:10.11114/jets.v3i5.947

iThemes Media. (2015). What is WordPress? Retrieved from https://ithemes.com/tutorials/what-iswordpress/

Leisyte, L., Westerheijden, D. F., Epping, E., Faber, M., \& De Weert, E. (2013, September). Stakeholders and quality assurance in higher education. Paper presented at the Center for Higher Education Policy Studies, Lausanne. Retrieved from http://doc.utwente.nl/87677/1/Stakeholders-QA-IBARCHER2013.pdf

Lester, S. (1999). An introduction to phenomenological research. Retrieved from https://www.rgs.org/NR/rdonlyres/F50603E0-41AF-4B15-9C84BA7E4DE8CB4F/0/Seaweedphenomenologyresearch.pdf

Mainardes, E., Alves, H., \& Raposo, M. (2013). Identifying stakeholders in a Portuguese university: A case study. Revista de Educación, 362, 17. doi:10.4438/1988-592X-RE-2012-362-167

Marelli, F.B. (2016). Qualitative research methods \& methodology. Retrieved from http://atlasti.com/qualitative-research-methods/

Martin, W. (Producer). (2010). Phenomenology beginnings and key themes. Retrieved from http://www.youtube.com/watch?v=Oev9GAm2MrI

Merfert, P. (2016). Report: The 2016 state of digital media in higher education. Retrieved from http://www.ednewsdaily.com/report-2016-state-digital-media-higher-education/ 
Moodle. (2015). About Moodle. Retrieved from https://docs.moodle.org/28/en/About_Moodle Built for learning.2C_globally

Moore, M. (1989). Three types of interaction. The American Journal of Distance Education, 3(2), 6. doi:10.1080/08923648909526659d

Moore, M. (2013). Handbook of distance education. New York, NY: Routledge.

Moskal, P., Dziuban, C., \& Hartman, J. (2013). Blended learning: A dangerous idea? The Internet and Higher Education, 18, 15-23. doi:10.1016/j.iheduc.2012.12.001

Moustakas, C. (1994). Phenomenology and human science inquiry. In Phenomenological research methods (pp. 43-68). Thousand Oaks, CA: Sage. doi:10.4135/9781412995658

Nicholls, D. (2009a). Qualitative research: Part one - Philosophies. International Journal of Therapy and Rehabilitation, 16(10), 526-533. doi:10.12968/ijtr.2009.16.10.44562

Nicholls, D. (2009b). Qualitative research: Part three - Methods. International Journal of Therapy and Rehabilitation, 16(11), 638-647. doi:10.12968/ijtr.2009.16.12.45433

Northern Illinois University. (2016). Tips for communicating effectively using Blackboard. Retrieved from http://www.niu.edu/blackboard/resources/communicatetips.shtml

Padilla-Diaz, M. (2015). Phenomenology in educational qualitative research: Philosophy as science or philosophical science? International Journal of Educational Excellence, 1(2), 101-110. doi:10.18562/IJEE.2015.0009

Panda, S., \& Mishra, S. (2007). E-learning in a mega open university: Faculty attitude, barriers and motivators. Educational Media International, 44(4), 323-338. doi:10.1080/09523980701680854

Passey, D. (2013). Inclusive technology enhanced learning: Overcoming cognitive, physical, emotional, and geographic challenges. London: Routledge.

Penner, J. L., \& McClement, S. E. (2008). Using phenomenology to examine the experiences of family caregivers of patients with advanced head and neck cancer: Reflections of a novice researcher. International Journal of Qualitative Methods, 7(2), 93101. Retrieved from https://ejournals.library.ualberta.ca/index.php/IJQM/article/download/1344/1353

Peppers, G. J. (2016). Higher education trends with focus on the future of teaching and learning. National Teacher Education Journal, 9(2), 87-94. Retrieved from Ebsco database.

Picciano, A. G. (2015). Planning for online education: A systems model. Online Learning, 19(5), 142158. Retrieved from https://olj.onlinelearningconsortium.org/index.php/olj/article/download/548/187

Power, T .M., \& Morven-Gould, A. (2011). Head of gold, feet of clay: The online learning paradox. International Review of Research in Open and Distance Learning, 12(2), 19-39. doi:10.19173/irrodl.v12i2.916 d

QSR International. (2015). NVivo 10 for Windows. Retrieved from http://www.qsrinternational.com/products_nvivo.aspx

Rawat, K. (2014, August 15). Phenomenology as a research method [Blog post]. Retrieved from http://rawat.blogspot.co.nz/2014/08/phenomenology-as-research-method.html

Reiners, G. M. (2012). Understanding the differences between Husserl's (descriptive) and Heidegger's (interpretive) phenomenological research. Journal of Nursing \& Care, 1(5). doi:10.4172/2167$\underline{1168.1000119}$

Saldana, J. (2011). Fundamentals of qualitative research. New York, NY: Oxford University Press. Retrieved from https://vivauniversity.files.wordpress.com/2014/02/saldana-2011-fundamentals-ofqualitative-research.pdf

Sanderson, M. (1997). Distance learning and best practice report (SafetyNet Esprit Project 23917). Retrieved from https://cordis.europa.eu/pub/esprit/docs/stsafety.doc

Simon, M. K., \& Goes, J. (2012). What is phenomenological research? Retrieved from http://dissertationrecipes.com/wp-content/uploads/2011/04/Phenomenological-Research.pdf

Singh, K., \& Weligamage, S. (2012, November). Thinking towards stakeholder satisfaction in higher education: An application of performance prism. Paper presented at the International Conference on Business and Information, Sri Lanka. Retrieved from http://www.kln.ac.lk/fcms/ICBI2012/images/ICBM/dccs/EDD006.pdf

Sloan, A., \& Bowe, B. (2014). Phenomenology and hermeneutic phenomenology: The philosophy, the methologies and using hermeneutic phenomenology to investigate lecturers' experiences of curriculum design. Quality \& Quantity, 48(3), 1291-1303. doi:10.1007/s11135-013-9835-3

Tang, S. F., \& Hussin, S. (2011). Quality in higher education: A variety of stakeholder perspectives. International Journal of Social Science and Humanity, 1(2), 126-131. doi:10.7763/IJSSH.2011.V1.21h 
Tuapawa, K. (2015, September). Resistance to change concerning the use of educational online technologies in blended tertiary environments. Paper presented at the The Fourth International Conference on E-Learning and E-Technologies in Education (ICEEE2015), Surya University, Tangerang. Retrieved from http://sdiwc.net/digital-library/resistance-to-change-concerning-use-ofeducational-online-technologies-in-blended-tertiary-environments.html

Tuapawa, K. (2016a). Challenges faced by key stakeholders using educational online technologies in blended tertiary environments. International Journal of Web-Based Learning and Teaching Technologies, 11(2). doi:10.4018/IJWLTT.2016040101

Tuapawa, K. (2016b). Identifying key stakeholders in blended tertiary environments. Manuscript submitted for publication.

Tuapawa, K. (2016c). Interpreting the experiences of students using educational online technologies to interact with students in blended tertiary environments: A phenomenological study. International Journal of Online Pedagogy and Course Design, 6(4), 38-52. doi:10.4018/IJOPCD.2016100103

Tuapawa, K. (in press). Educational online technologies in blended tertiary environments: Experts' perpectives. International Journal of Communication and Information Technology Education, 13(3).

Tuapawa, K., Sher, W., \& Gu, N. (2014). Pentexonomy: A multi-dimensional taxonomy of educational online technologies. International Journal of Web-Based Learning and Teaching Technologies, 9(1), 41-59. doi:10.4018/ijwltt.2014010104

Tuapawa, K., Sher, W., \& Gu, N. (2016). Pentexonomy: A multi-dimensional taxonomy of educational online technologies. In M. Raisinghani (Ed.), Revolutionizing education through web-based instruction (pp. 225-252). Hershey, PA: IGI Global.

Voyton, A. (Producer). (2014). Web design, accessibility, and usability tips in Blackboard. Retrieved from http://www.slideshare.net/WilmUedtech/web-design-accessibility-and-usability-tips

Wagner, N., Hassanein, K., \& Head, M. (2008). Who is responsible for e-learning success in higher education? A stakeholders' analysis. Journal of Educational Technology \& Society, 11(3), 26-36. Retrieved from ERIC database. (EJ814115)

Waters, J. (2016). Phenomenological research guidelines. Retrieved from https://www.capilanou.ca/psychology/student-resources/research-guidelines/PhenomenologicalResearch-Guidelines/

Wikispaces. (2015). Introduction. Retrieved from https://www.wikispaces.com/content/classroom/about

Williams, A. (2003). How to write and analyse a questionnaire. Journal of Orthodontics, 30(3), 245-252. doi:10.1093/ortho/30.3.245

Yang, Y., \& Cornelious, L. F. (2005). Preparing instructors for quality online instruction. Online Journal of Distance Learning Administration, 8(1), 363-369. Retrieved from http://www.westga.edu/ distance/ojdla/spring81/yang81.htm

Yin, R. K. (2015). Qualitative research from start to finish. New York, NY: Gilford Publications.

Yuksel, P., \& Yildirim, S. (2015). Theoretical frameworks, methods, and procedures for conducting phenomenological studies in educational settings. Turkish Online Journal of Qualitative Inquiry, 6(1), 1-20. Retrieved from http://dergipark.ulakbim.gov.tr/tojqi/article/view/5000093521/5000087061

Corresponding author: Kimberley Tuapawa, ktuapawa@slingshot.co.nz

Australasian Journal of Educational Technology (c) 2017.

Please cite as: Tuapawa, K. (2017). Interpreting experiences of students using educational online technologies to interact with teachers in blended tertiary environments: A phenomenological study. Australasian Journal of Educational Technology, 33(1), 163-175. https://doi.org/10.14742/ajet.2964 